\title{
Clinical and Laboratory Factors Associated with Severe Disease Course in Turkish Patients with COVID-19 Infection
}

\author{
Çağatay Ak ${ }^{1, *}$, Süleyman Sayar¹, Zeynep Pelin Polat², Ebru Tarıkçı Kılıç³ and Kamil Özdil ${ }^{1}$ \\ 1 Department of Gastroenterology, University of Health Sciences, Umraniye Training and Research Hospital, Istanbul, Turkey \\ 2 Department of Internal Medicine, University of Health Sciences, Umraniye Training and Research Hospital, Istanbul, Turkey \\ 3 Department of Anesthesiology, University of Health Sciences, Umraniye Training and Research Hospital, Istanbul, Turkey
}

* Corresponding author: Çağatay Ak, Department of Gastroenterology, University of Health Sciences, Umraniye Training and Research Hospital, Istanbul, Turkey. Email: cagatayak88@gmail.com

Received 2020 November 19; Revised 2020 December 23; Accepted 2021 January 09.

\begin{abstract}
Background: Coronavirus disease 2019 (COVID-19) can have a wide clinical spectrum.

Objectives: The current study aimed to analyze the clinical and laboratory risk factors of the severe course of disease in patients with COVID-19.

Methods: Consecutive patients with a diagnosis of COVID-19 pneumonia were included in the present study. The demographic characteristics, comorbid diseases, symptoms, chest computed tomography (CT) findings, laboratory data, oxygen saturation $\left(\mathrm{Sp} \mathrm{O}_{2}\right)$, and body temperature of the patients were recorded. The coexistence of pulmonary infiltration in CT and $\mathrm{SpO}_{2}$ of $\leq \% 93$ on fingertip pulse oximeter was defined as the severe course of the disease.

Results: A total of 475 patients were included in the current study. The mean age of the patients was $52.02 \pm 15.9$ years, and 259 (54.5\%) participants were male. The disease was mild and severe in $80 \%(\mathrm{n}=380)$ and $20 \%(\mathrm{n}=95)$ of the study subjects, respectively. The age of $>$ 50 years, coexistence of hypertension (HT) and diabetes mellitus (DM), neutrophil-to-lymphocyte ratio (NLR) of $>4$, lactate dehydrogenase (LDH) of $>240 \mathrm{U} / \mathrm{L}$, C-reactive protein (CRP) of $>8 \mathrm{mg} / \mathrm{dL}$, and D-dimer of $\geq 1000 \mathrm{ng} / \mathrm{mL}$ were determined to be the risk factors for the severe course of the disease.

Conclusion: Age, NLR, CRP, LDH, D-dimer, comorbidity, and coexistence of DM and HT were the independent risk factors for the severe course of the disease. The aforementioned factors should be taken into account during risk stratification and management of patients with COVID-19.

Keywords: COVID-19, Risk factors of severe pneumonia, SARS-CoV-2, Severe disease
\end{abstract}

\section{Background}

An outbreak of pneumonia with unknown etiology occurred in Wuhan, which is the center of Hubei province in China, in November 2019 (1). In January 2020, Chinese scientists isolated a new coronavirus called 2019 novel coronavirus (later named severe acute respiratory syndrome coronavirus 2), which causes severe acute respiratory failure (2). The World Health Organization later named the disease caused by this virus coronavirus disease 2019 (COVID-19) (3).

The COVID-19 infection has a wide clinical spectrum from asymptomatic carriers to acute respiratory distress syndrome (ARDS) and multiorgan failure (4). The COVID-19 replicates by entering into the nasal epithelium via the angiotensin-converting enzyme 2 receptor (5). Then, the virus multiplies in the respiratory tract along the airways within the next few days and the innate immune system is triggered. The disease resolves by limiting itself in the vast majority of patients.

In a small number of patients, type II alveolar cells are affected and pulmonary infiltrates develop. In addition, some of these patients develop a more severe course of the disease. Both the uncontrolled activation of the innate immune system and weak response of the adaptive immune system in these patients are associated with local and systemic tissue damage. This situation is characterized by widespread alveolar damage, alveolar cell infiltration, and alveolar cell apoptosis worsening up to the occurrence of ARDS and mortality (4).

Currently, there is no proven specific treatment option with an antiviral effect that can stop the spread of the pandemic or change the course of the disease. However, it is known that hyperinflammation or cytokine release syndrome that is induced by COVID-19 is an important cause of morbidity and mortality in some patients (1). The analysis of the clinical and laboratory findings of patients with regard to the severe course of the disease can provide important data about potential treatment options (i.e., potential antivirals and treatments for cytokine storm) that should be exercised for COVID19 patients (6).

\section{Objectives}

The current study aimed to analyze clinical and laboratory risk factors and indicators of the severe course of the disease in patients with COVID-19. 


\section{Methods}

The present study was conducted on consecutive patients who were diagnosed with COVID-19 infection and hospitalized in Umraniye Training and Research Hospital, which served as a Pandemic hospital, at Health Sciences University, Istanbul, Turkey, within March 11 and April 15, 2020. The COVID-19 infection was diagnosed via the detection of COVID-19 by reverse transcriptase-polymerase chain reaction (RT-PCR) in the samples that were taken through nasal or pharyngeal swabbing, acute lower respiratory tract complaints that were not associated with any other etiological cause, history of contact with an infected individual with a proven COVID-19 infection within the previous 2 weeks, and visualization of typical signs of viral pneumonia on a chest computed tomography (CT) scan.

The recorded data included the demographic characteristics, comorbid diseases, symptoms on admission, symptom duration, swab COVID-19 PCR results, white blood cell (WBC) count, lymphocyte count (LC), neutrophil count (NC), neutrophil-tolymphocyte ratio (NLR), lactate dehydrogenase (LDH), alanine aminotransferase (ALT), aspartate aminotransferase (AST), creatinine, urea, albumin, D-dimer, procalcitonin parameters, oxygen saturation $\left(\mathrm{SpO}_{2}\right)$, body temperature at the time of hospitalization, and chest CT findings of the patients. The $\mathrm{SpO}_{2}$ value and body temperature of all the patients were monitored and recorded in at least 12hour intervals. Laboratory parameters (i.e., WBC, LC, NC, C-reactive protein [CRP], LDH, ALT, AST, creatinine, urea, and D-dimer) were also recorded on posthospitalization days 1-3 and 5 .

The severe course of the disease (severe pneumonia) according to the national COVID-19 guidelines is defined as an $\mathrm{SpO}_{2}$ level of $\leq 93 \%$ measured from the fingertip in room air and presence of lung infiltration on chest CT. The patients were classified as having nonsevere or severe disease according to the findings that were evaluated during hospitalization. The subjects in the COVID-19 patient group with severe disease who died were defined as nonsurvivors. The patients under 18 years of age, with no radiological findings of pneumonia at the time of hospitalization and during monitoring or with no hospitalization, and those with missing clinical and laboratory data were not included in the study. The present study was approved by the Local Ethics Board of Umraniye Training and Research Hospital on April 28, 2020 (decision No. B.10.1.TKH. 4.34.H.GP.0.01/135).

\subsection{Statistical analysis}

The data were analyzed using SPSS software (version 25.0). Descriptive statistics (e.g., mean, standard deviation, minimum, median, and maximum) were used to define continuous variables. The distribution of the data according to the number of samples was evaluated using the Kolmogorov-Smirnov test. The Mann-Whitney $\mathrm{U}$ test and Kruskal-Wallis $\mathrm{H}$ test were used to compare two continuous variables with nonnormal distribution. The t-test and one-way analysis of variance were utilized for normally distributed data. The diagnostic performance of laboratory parameters in the determination of the severe course of the disease was evaluated using receiver operating curve analysis. Pearson's correlation analysis and Spearman's correlation analysis were used for the determination of the relationship between the quantitative data. A pvalue of less than 0.05 was considered statistically significant, and the results were given within a 95\% confidence interval (CI). Parameters that were observed to be statistically significant and not correlated with each other in the univariate analysis were evaluated using logistic regression analysis.

\section{Results}

The COVID-19 infection was diagnosed in 629 patients who were admitted to the Umraniye Training and Research Hospital within March 11 and April 6, 2020. Out of 629 patients, 475 subjects with pneumonia due to COVID-19 infection who were hospitalized were included in the study, and 154 patients with no pneumonia or no need for hospitalization were not included in the study. The mean age of the study subjects was $52.02 \pm 15.9$ years (range: $18-93$ years), and 259 patients (54.5\%) were male. Furthermore, $55.9 \%(\mathrm{n}=218)$ of the subjects were PCR-positive for COVID-19. The average symptom duration of the patients was reported as 4.92 days (range: $0-20$ days).

The disease was mild and severe in $80 \%(n=380)$ and $20 \% \quad(n=95)$ of the patients, respectively. Moreover, $4.6 \%(n=22)$ of the study subjects died due to COVID-19 infection. Three patient groups were determined based on the course of the disease, including patients with a mild course $(n=380)$, survivors with a severe course $(\mathrm{n}=73)$, and nonsurvivors with a severe course $(n=22)$. Table 1 shows the patients' demographic characteristics, symptoms, and radiological findings at the time of admission and a comparison of these parameters and course of the disease. The frequency of the patients with severe disease and comorbid diseases, such as hypertension (HT) and dyspnea, was significantly high. In addition, the subjects with severe disease who died had higher body temperature and lower $\mathrm{SpO}_{2}$ values on admission.

Table 2 tabulates the recorded laboratory values of the patients on admission and comparison of these values using the tests performed in the course of the disease. Figure 1 illustrates the comparison of laboratory parameters, $\mathrm{SpO}_{2}$ levels, and body 


\begin{tabular}{|c|c|c|c|c|c|}
\hline \multirow[b]{2}{*}{ Parameter } & \multirow{2}{*}{$\begin{array}{c}\text { Nonsevere } \\
\text { n (\%) }\end{array}$} & \multicolumn{2}{|c|}{ Severe } & \multirow[b]{2}{*}{ P-value } & \multirow[b]{2}{*}{ All patients } \\
\hline & & $\begin{array}{c}\text { Survivors } \\
\text { n (\%) }\end{array}$ & $\begin{array}{c}\text { Nonsurvivors } \\
\text { n (\%) }\end{array}$ & & \\
\hline Number of patients & $380(80)$ & $73(15.4)$ & $22(4.6)$ & N/A & 475 \\
\hline \multicolumn{6}{|l|}{ General features } \\
\hline Age (mean \pm standard deviation) & $61.15 \pm 16.5$ & $64.82 \pm 12.1$ & $49.52 \pm 14.9$ & $<0.001$ & $52.02( \pm 15.9)$ \\
\hline \multirow{2}{*}{ Gender } & $202(53.2)$ & $43(58.9)$ & $14(63.6)$ & 0.452 & $259(54.5)$ \\
\hline & $178(46.8)$ & $30(41.1)$ & $8(36.4)$ & 0.498 & $216(45.5)$ \\
\hline Smoking & $103(27.1)$ & $18(24.7)$ & $8(36.4)$ & 0.556 & $129(27.2)$ \\
\hline Alcohol & $30(7.9)$ & $3(4.1)$ & - & 0.214 & $33(6.9)$ \\
\hline \multicolumn{6}{|l|}{ Comorbid disease } \\
\hline Hypertension & $95(25)$ & $26(35.6)$ & $12(54.5)$ & 0.003 & $133(28)$ \\
\hline CAD & $23(6.1)$ & $9(12.3)$ & $2(9.1)$ & 0.153 & $34(7)$ \\
\hline COPD & $19(5)$ & $9(12.3)$ & $2(9.1)$ & N/A & $30(6)$ \\
\hline Asthma & $27(7.1)$ & $1(1.4)$ & - & $\mathrm{N} / \mathrm{A}$ & $28(5.8)$ \\
\hline CRF & $5(1.3)$ & $6(8.2)$ & $3(13.6)$ & $\mathrm{N} / \mathrm{A}$ & 14 \\
\hline DM & 65 (17.1) & $16(21.9)$ & $8(36.4)$ & 0.06 & 89 \\
\hline Malignancy & $12(3.2)$ & $2(2.7)$ & $1(4.5)$ & N/A & 15 \\
\hline Rheumatological disease & $6(1.6)$ & $2(2.7)$ & - & $\mathrm{N} / \mathrm{A}$ & 8 \\
\hline Other & $21(5.5)$ & $15(20.5)$ & $5(22.7)$ & N/A & 41 \\
\hline \multicolumn{6}{|l|}{ Presenting symptoms } \\
\hline Fever & $177(46.6)$ & $40(54.8)$ & $12(54.5)$ & 0.363 & $229(48.2)$ \\
\hline Cough & $252(66.3)$ & $56(76.7)$ & $17(77.3)$ & 0.142 & $325(68.4)$ \\
\hline Dyspnea & 71 (18.7) & $14(19.2)$ & 13 (59.1) & $<0.001$ & $98(20.6)$ \\
\hline Fatigue & $96(25.3)$ & $28(38.4)$ & $2(9.1)$ & $\mathrm{N} / \mathrm{A}$ & $126(33.6)$ \\
\hline Myalgia & $53(13.9)$ & $8(11)$ & $1(4.5)$ & 0.377 & $62(13)$ \\
\hline Diarrhea & $25(6.6)$ & $5(6.8)$ & $1(4.5)$ & $\mathrm{N} / \mathrm{A}$ & $31(6.5)$ \\
\hline \multicolumn{6}{|l|}{ Body temperature and $\mathrm{SpO}_{2}$} \\
\hline Body temperature $\left({ }^{\circ} \mathrm{C}\right)$ & $37.6 \pm 0.99$ & $37.6 \pm 0.96$ & $38 \pm 1.15$ & 0.032 & $\mathrm{~N} / \mathrm{A}$ \\
\hline $\mathrm{SpO}_{2}$ & $97 \pm 1.58$ & $92 \pm 2.62$ & $90 \pm 5.03$ & $<0.001$ & $\mathrm{~N} / \mathrm{A}$ \\
\hline \multicolumn{6}{|l|}{ Radiological findings } \\
\hline Pulmonary & $82(21.6)$ & - & - & $<0.001$ & $82(21.6)$ \\
\hline involvement (CT) $\quad$ Bilateral & $298(78.4)$ & $73(100)$ & $22(100)$ & $\mathrm{N} / \mathrm{A}$ & \\
\hline
\end{tabular}

Table 2. Laboratory values of patients on admission and comparison of these values using the tests performed during the course of the disease

\begin{tabular}{|c|c|c|c|c|}
\hline Parameter & Nonsevere & Severe survivors & Severe nonsurvivors & P-value \\
\hline Leukocyte $\left(10^{3} \mu / L\right)$ & $6125 \pm 3912.8$ & $5950 \pm 4156.29$ & $7430 \pm 4486.71$ & 0.054 \\
\hline NC $\left(10^{3} \mu / L\right)$ & $3900 \pm 3388.8$ & $4260 \pm 3890.89$ & $5890 \pm 4321.97$ & 0.001 \\
\hline LC $\left(10^{3} \mu / L\right)$ & $1480 \pm 744.4$ & $1190 \pm 613.10$ & $840 \pm 476.89$ & $<0.001$ \\
\hline NLR & $2.64 \pm 4.49$ & $3.95 \pm 4.26$ & $6.879 \pm 5.07$ & $<0.001$ \\
\hline $\mathrm{Hb}(\mathrm{g} / \mathrm{dL})$ & $13.5 \pm 1.66$ & $12.6 \pm 1.94$ & $12.5 \pm 1.78$ & 0.002 \\
\hline $\operatorname{PLT}\left(10^{3} \mu / \mathrm{L}\right)$ & $203 \pm 77.52$ & $179 \pm 81.46$ & $191.5 \pm 100.3$ & 0.051 \\
\hline MPV (f/L) & $9.6 \pm 1.08$ & $10 \pm 1.16$ & $9.4 \pm 1.64$ & 0.349 \\
\hline CRP (mg/dL) & $1.8 \pm 4.52$ & $7.8 \pm 6.07$ & $10.9 \pm 7.06$ & $<0.001$ \\
\hline Albumin $(\mathrm{g} / \mathrm{L})$ & $4.18 \pm 0.38$ & $3.93 \pm 4.33$ & $3.61 \pm 0.49$ & $<0.001$ \\
\hline Creatinine (mg/dL) & $0.81 \pm 0.52$ & $0.89 \pm 0.87$ & $1.005 \pm 1.18$ & $<0.001$ \\
\hline BUN (mg/dL) & $25.6 \pm 17.12$ & $34.2 \pm 39.08$ & $43.85 \pm 36.15$ & $<0.001$ \\
\hline ALT (IU/L) & $23 \pm 28.52$ & $24 \pm 20.37$ & $19.5 \pm 16.9$ & 0.347 \\
\hline AST (IU/L) & $25 \pm 20.41$ & $31 \pm 17.20$ & $31 \pm 38.6$ & 0.002 \\
\hline LDH (U/L) & $268 \pm 95.57$ & $336 \pm 106.82$ & $374.5 \pm 325.1$ & $<0.001$ \\
\hline Procalcitonin (ng/m) & $0.05 \pm 4.92$ & $0.05 \pm 3.62$ & $0.23 \pm 0.68$ & $<0.001$ \\
\hline D-dimer (ng/mL) & $530 \pm 826.99$ & $1510 \pm 919.08$ & $1555 \pm 2273.4$ & $<0.001$ \\
\hline
\end{tabular}

temperatures of the patients on posthospitalization days 1,3 , and 5 with the course of the disease. The clinical and laboratory risk factors of the patients (survivors and nonsurvivors) with a severe course of the disease were evaluated using logistic regression analysis, and Table 3 shows the results of the analysis.

\section{Discussion}

The COVID-19 infection has a wide clinical spectrum from asymptomatic carriers to ARDS and multiorgan failure (4). Although most patients have a nonsevere clinical picture, progressive severe 

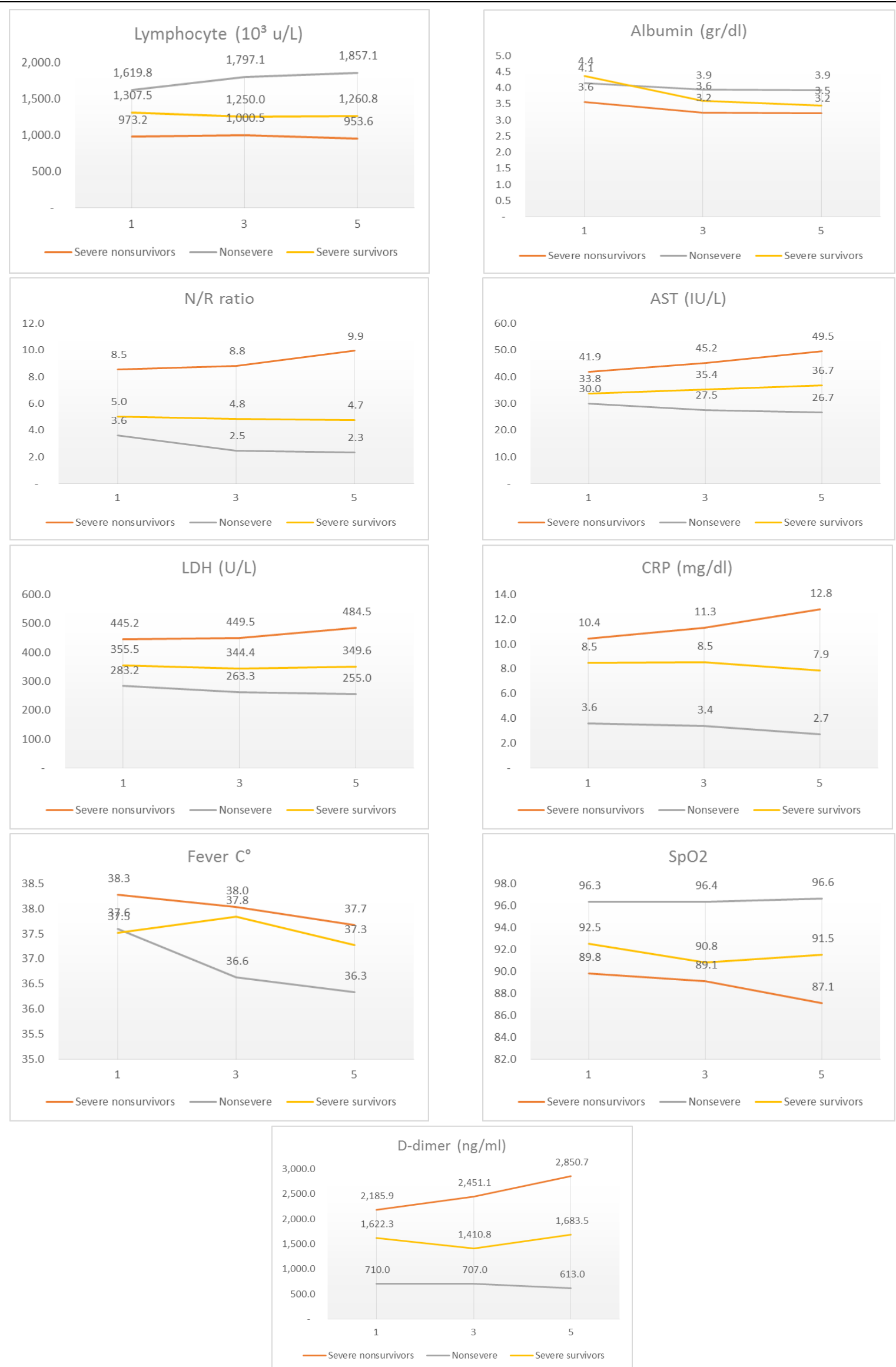

Figure 1. Comparison of laboratory parameters, oxygen saturation levels, and body temperatures of patients on posthospitalization days 1,3 , and 5 with course of the disease 


\begin{tabular}{|c|c|c|c|c|c|c|c|c|c|}
\hline \multicolumn{10}{|c|}{$\begin{array}{c}\text { Variables in the equation } \\
95 \% \text { CI for EXP (B) }\end{array}$} \\
\hline & & B & S.E. & Wald & Df & Sig. & $\operatorname{Exp}(B)$ & Lower & Upper \\
\hline Type & Parameter & & & & & & & & \\
\hline \multirow{2}{*}{ Step 1a } & Age $>50$ years & 1.206 & 0.348 & 12.001 & 1 & 0.001 & 3.339 & 1.688 & 6.605 \\
\hline & Constant & 0.636 & 0.168 & 14.281 & 1 & $<0.001$ & 1.889 & & \\
\hline \multirow{3}{*}{ Step 1b } & DM and HT & 0.638 & 0.234 & 7.454 & 1 & 0.006 & 1.892 & 1.197 & 2.991 \\
\hline & Constant & 0.995 & 0.176 & 31.798 & 1 & $<0.001$ & 2.705 & & \\
\hline & Body temperature $\geq 38^{\circ} \mathrm{C}$ & 0.081 & 0.368 & 0.048 & 1 & 0.826 & 0.922 & 0.449 & 1.896 \\
\hline \multirow{11}{*}{ Step 1c } & $W B C \geq 10,000\left(10^{3} \mu / L\right)$ & -0.494 & 0.578 & 0.730 & 1 & 0.393 & 0.610 & 0.196 & 1.895 \\
\hline & $\mathrm{NC} \geq 6,000\left(10^{3} \mu / \mathrm{L}\right)$ & -0.754 & 0.535 & 1.989 & 1 & 0.158 & 0.470 & 0.165 & 1.342 \\
\hline & $\mathrm{LC} \leq 800\left(10^{3} \mu / \mathrm{L}\right)$ & 0.117 & 0.466 & 0.063 & 1 & 0.802 & 1.124 & 0.451 & 2.798 \\
\hline & $\mathrm{NLR}>4$ & 0.892 & 0.396 & 5.088 & 1 & 0.024 & 2.441 & 1.124 & 5.299 \\
\hline & Albumin<3.5 (g/L) & -0.262 & 0.453 & 0.336 & 1 & 0.562 & 0.769 & 0.317 & 1.868 \\
\hline & Creatinine $\geq 1.5(\mathrm{mg} / \mathrm{dL})$ & 0.960 & 0.597 & 2.585 & 1 & 0.108 & 2.612 & 0.810 & 8.422 \\
\hline & $\mathrm{AST} \geq 50$ & -0.072 & 0.484 & 0.022 & 1 & 0.882 & 0.930 & 0.360 & 2.403 \\
\hline & LDH>240 (U/L) & 1.521 & 0.474 & 10.283 & 1 & 0.001 & 4.575 & 1.806 & 11.589 \\
\hline & D-dimer $\geq 1,000(\mathrm{ng} / \mathrm{mL})$ & 2.572 & 0.325 & 62.755 & 1 & $<0.001$ & 13.098 & 6.931 & 24.753 \\
\hline & $\mathrm{CRP} \geq 8(\mathrm{mg} / \mathrm{dL})$ & 1.041 & 0.380 & 7.524 & 1 & 0.006 & 2.833 & 1.346 & 5.961 \\
\hline & Constant & -1.319 & 0.767 & 2.953 & 1 & 0.086 & 0.267 & & \\
\hline
\end{tabular}

pneumonia is observed in approximately $15 \%$ of the patients. Furthermore, ARDS, septic shock, and multiorgan failure develop in approximately $5 \%$ of the patients $(7,8)$.

In the present retrospective cohort study, it was noticed that $20 \%$ of the subjects had severe disease and the mortality rate was reported as $4.6 \%$. The average age values of the nonsevere and severe patients were similar. Nevertheless, it was observed that the age of $>50$ years was an independent risk factor for the severe disease $(\mathrm{OR}=3.339$; $95 \% \mathrm{CI}$ : 1.688-6.605; $\mathrm{P}=0.001)$. The evidence supports that older ages are associated with a poor prognosis. The adverse effects of older age on prognosis, weakening of viral replication control, uncontrolled activation of the innate immune system, and prolonged inflammatory response have all been associated with the weakening of tissue repair mechanisms $(3,9)$.

Among the present study population, $52.6 \%$ of the patients had at least one comorbid disease. The most common comorbid diseases were HT (28\%), coronary artery disease (CAD) (27.5\%), chronic obstructive pulmonary disease (COPD) (26.4\%), and diabetes mellitus (DM) (18\%). However, the frequency of patients with HT was significantly higher in those with severe disease and nonsurvivor group.

The initial data from China have shown that HT and other cardiovascular diseases are common (within the range of approximately 4.5-30\%) in patients with COVID-19 infection. This has raised concerns that HT and other cardiovascular diseases may be associated with a poor prognosis. Although many studies reported that patients with a poor prognosis have a high prevalence of HT, this finding has been assessed using multivariate analysis in a limited number of studies (10). A study carried out by Guan et al. evaluated 1,590 patients and showed that the subjects with HT, DM, COPD, and malignancy (after adjustment based on age and smoking status) were more likely to reach endpoints, such as intensive care, mechanical ventilation, and mortality. In addition, the results of the aforementioned study demonstrated that the presence of two or more comorbid diseases increases the risk of adverse outcomes (11).

Zhou et al. reported that HT, DM, CAD, chronic renal failure, and COPD are more common in nonsurvivors. Nonetheless, these comorbid factors were observed to be unrelated to mortality after age adjustment (3). In a meta-analysis, a significant correlation was noticed between COVID-19 severity and diabetes (OR=2.67; 95\% CI: 1.91-3.74; $\mathrm{P}<0.01)$ (12). Moreover, in another meta-analysis, HT was observed to increase the mortality risk in COVID-19 by 2.5 times $\left(\mathrm{OR}=2.42 ; 95 \% \mathrm{CI}\right.$ : $\left.1.51-3.90 ; \mathrm{I}^{2}=0 \%\right)$ (13). In the present study, it was noticed that the coexistence of HT and DM increased the risk of severe disease as an independent factor (OR=1.89; 95\% CI: 1.197-2.99; $\mathrm{P}=0.006)$. The frequency rates of the patients with both HT and DM were $16.4 \%$ and $27.2 \%$ in the survivor and nonsurvivor groups with a severe course of the disease, respectively (data not shown in the Results section).

More patients significantly presented with dyspnea in the group of subjects with a severe course of the disease in this cohort study. Although $\mathrm{SpO}_{2}$ was used to detect severe and nonsevere patients, the rates of $\mathrm{SpO}_{2}$ and dyspnea symptoms were significantly lower and higher in the nonsurviving group with severe disease than those of nonsevere patients, respectively. Lower $\mathrm{SpO}_{2}$ values and dyspnea as a subjective symptom are among the indicators reflecting the severity and prevalence of pulmonary injury, which is the most prominent end- 
organ involvement of COVID-19 infection (11).

In a meta-analysis conducted by Izcovich A et al., the presence of dyspnea was defined as a very important risk factor for the disease progression $(\mathrm{OR}=21.17 ; 95 \% \mathrm{CI}: 4.9-91.3$; $\mathrm{RD}=20.3 \%$; 95\% CI: 13.4-22.4) (14). In addition, in this study, it was observed that patients with severe disease had higher mean body temperature at presentation and during the first 5-day course of fever than those without severe disease. Izcovich $\mathrm{A}$ et al. concluded that high fever (OR=1.84; 95\%: CI 1.54-2.21; $\mathrm{RD}=6.1 \%$; 95\% CI: 4.5-7.6) was a risk factor associated with poor prognosis. (14). The aforementioned findings demonstrated that patients with severe disease in these cohorts have higher levels of inflammatory stress that causes inflammatory response and organ damage.

It was observed that the mean body temperature, especially in the nonsurvivor group, was above $38^{\circ} \mathrm{C}$ in the first $72 \mathrm{~h}$ after admission. In addition, in this study, it was noticed that the mean NC, NLR, creatinine, blood urea nitrogen, LDH and procalcitonin levels were significantly higher and LC and albumin levels were significantly lower at presentation in severe patients, compared to those reported for the nonsevere subjects. It was observed that an NLR of > 4 (OR=2.441; 95\% CI: 1.124-5.299; $\mathrm{P}=0.024$ ), high LDH (>upper limit of normal) (OR=4.575; 95\% CI: 1.806-11.589; $\mathrm{P}=0.001)$, and CRP of > $8 \quad(\mathrm{OR}=2.833$; 95\% CI: 1.346-5.961; $\mathrm{P}=0.006$ ) were the independent risk factors for the severe course of the disease. In two different metaanalyses, high levels of CRP (OR=6.6; 95\% CI: 3.3612.99), LDH (OR=3.66; 95\% CI: 2.26-5.94), and NLR $(\mathrm{OR}=2.50$; 95\% CI: 2.04-3.06) were observed to be the risk factors for the severe course of the disease $(14,15)$.

According to the literature, a high NC and low LC have been associated with severe disease course. The severe inflammatory response that can occur during COVID-19 causes natural and adaptive immune response instability. Therefore, inflammatory biomarkers reflecting inflammation and immune status are potential predictors for the prognosis of patients with this disease (16). Yang et al. reported that NLR is an independent risk factor for the severe course of the disease; however, Liu et al. showed that NLR predicted critical disease $(16,17)$.

In another study, Di Micco et al. evaluated hemostatic alterations and showed that a high D-dimer value during COVID-19 infection was associated with increased thromboembolic tendency since the early stage of infection (18). In a study carried out by Zhou et al., it was reported that high Ddimer levels are associated with a poor prognosis (3). In the present cohort study, it was observed that a Ddimer level of $\geq 1000 \mathrm{ng} / \mathrm{mL}$ at presentation was an independent risk factor for the severe course of the disease (OR=13.09; 95\% CI: 6.931-24.753; $\mathrm{P}=0.000$ ).
A D dimer of $\geq 500 \mathrm{ng} / \mathrm{mL}$ was detected as an indicator for the severity of the disease in another study (OR=43.24; 95\% CI: 9.92-188.49; $\mathrm{P}<0.00001$ ) (19). In this study, it was also shown that the diagnostic performance of D-dimer (cut-off: 819.5 $\mathrm{ng} / \mathrm{mL}$ ) was better than all the laboratory parameters that were tested (area under the curve $=0.850$; sensitivity $=81 \%$; specificity $=77 \%$; $95 \%$ CI: 0.800 $0.900 ; \mathrm{P}=0.000$ ) for the diagnosis of the severe course of the disease (the data not included in the Results section).

The current study had several limitations. The first limitation was its retrospective design and inclusion of single-center data. Additionally, the parameters, such as ferritin and interleukin 6, which may be important for the patient's prognosis, could not be analyzed. Moreover, $44.1 \%$ of the patients were RT-PCR-negative; nonetheless, all the PCRnegative subjects had a history of contact with a PCRpositive patient.

\section{Conclusion}

In conclusion, the clinical and laboratory characteristics that were associated with a severe clinical course of the disease in Turkish patients with COVID-19 were analyzed in this study. It was observed that age, CRP, LDH, NLR, D-dimer, and comorbid DM and HT combination were the independent risk factors for the severe course of the disease according to the cut-off points determined in the present study. The aforementioned factors should be taken into account during risk stratification and management of patients with COVID-19.

\section{Acknowledgments}

None declared.

\section{Footnotes}

Authors' Contribution: Concept: Süleyman Sayar and Çağatay Ak; Design: Süleyman Sayar and Kamil Özdil; Supervision: Süleyman Sayar; Resources: Çağatay Ak and Zeynep Pelin Polat; Materials: Ebru Tarıkçı Kılıç; Data Collection and/or Processing: Çağatay Ak and Zeynep Pelin Polat; Analysis and/or Interpretation: Süleyman Sayar and Çağatay Ak; Literature Search: Süleyman Sayar and Çağatay Ak; Writing Manuscript: Çağatay $\mathrm{Ak}$ and Süleyman Sayar; Critical Review: Ebru Tarıkçı Kılıç and Kamil Özdil

Conflict of Interests: None declared.

Ethical Approval: The present study was approved by the Local Ethics Board of Ümraniye Training and Research Hospital on April 28, 2020 (decision No. B.10.1.TKH.4.34.H.GP.0.01/135).

Informed consent: This study was a data scanning investigation prepared on a retrospective basis. 


\section{References}

1. Soy M, Keser G, Atagündüz P, Tabak F, Atagündüz I, Kayhan S, et al. Cytokine storm in COVID-19: pathogenesis and overview of anti-inflammatory agents used in treatment. Clin Rheumatol. 2020;39(7):2085-94. doi: 10.1007/s10067-020-05190-5. [PubMed: 32474885].

2. Coronaviridae Study Group of the International Committee on Taxonomy of Viruses. The species severe acute respiratory syndrome-related coronavirus: classifying 2019-nCoV and naming it SARS-CoV-2. Nat Microbiol. 2020;5(4):536-44. doi: 10.1038/s41564-020-0695-z. [PubMed: 32123347].

3. Zhou F, Yu T, Du R, Fan G, Liu Y, Liu Z, et al. Clinical course and risk factors for mortality of adult inpatients with COVID-19 in Wuhan, China: a retrospective cohort study. Lancet. 2020; 395(10229):1054-62. doi: 10.1016/S0140-6736(20)30566-3. [PubMed: 32171076].

4. Wu Z, McGoogan JM. Characteristics of and important lessons from the coronavirus disease 2019 (COVID-19) outbreak in China: summary of a report of 72314 cases from the Chinese center for disease control and prevention. JAMA. 2020; 323(13):1239-42. doi: 10.1001/jama.2020.2648. [PubMed: 32091533].

5. Wan Y, Shang J, Graham R, Baric RS, Li F. Receptor recognition by novel coronavirus from Wuhan: An analysis based on decade-long structural studies of SARS. J Virol. 2020; 94(7):e00127-20. doi: 10.1128/JVI.00127-20. [PubMed: 31996437].

6. Stebbing J, Phelan A, Griffin I, Tucker C, Oechsle O, Smith D, et al. COVID-19: combining antiviral and anti-inflammatory treatments. Lancet Infect Dis. 2020;20(4):400-2. doi: 10.1016/S1473-3099(20)30132-8. [PubMed: 32113509].

7. Xu Z, Shi L, Wang Zhang J, Huang L, Zhang C, et al. Pathological findings of COVID-19 associated with acute respiratory distress syndrome. Lancet Respir Med. 2020;8(4):420-2. doi: 10.1016/S2213-2600(20)30076-X. [PubMed: 32085846].

8. Qin C, Zhou L, Hu Z, Zhang S, Yang S, Tao Y, et al. Dysregulation of immune response in patients with coronavirus 2019 (COVID-19) in Wuhan, China. Clin Infect Dis. 2020;71(15):7628. doi: 10.1093/cid/ciaa248. [PubMed: 32161940].

9. Opal SM, Girard TD, Ely EW. The immunopathogenesis of sepsis in elderly patients. Clin Infect Dis. 2005;41(Suppl 7):S504-12. doi: 10.1086/432007. [PubMed: 16237654].

10. Tadic M, Cuspidi C, Mancia G, Dell'Oro R, Grassi G. COVID-19, hypertension and cardiovascular diseases: should we change the therapy? Pharmacol Res. 2020;158:104906. doi: 10.1016/ j.phrs.2020.104906. [PubMed: 32461198].

11. Guan WJ, Liang WH, Zhao Y, Liang HR, Chen ZS, Li YM, et al China medical treatment expert group for covid-19. Comorbidity and its impact on 1590 patients with COVID-19 in China: a nationwide analysis. Eur Respir J. 2020;55(5): 2000547. doi: 10.1183/13993003.00547-2020. [PubMed: 32217650].

12. Chen Y, Gong X, Wang L, Guo J. Effects of hypertension, diabetes and coronary heart disease on COVID-19 diseases severity: a systematic review and meta-analysis. MedRxiv. 2020;3:1-12. doi: 10.1101/2020.03.25.20043133.

13. Lippi G, Wong J, Henry BM. Hypertension in patients with coronavirus disease 2019 (COVID-19): a pooled analysis. Pol Arch Intern Med. 2020;130(4):304-9. doi: 10.20452/pamw.15272. [PubMed: 32231171].

14. Izcovich A, Ragusa MA, Tortosa F, LavenaMarzio MA, Agnoletti C, Bengolea A, et al. Prognostic factors for severity and mortality in patients infected with COVID-19: a systematic review. PLoS One. 2020;15(11):e0241955. doi: 10.1371/ journal.pone.0241955. [PubMed: 33201896].

15. Feng X, Li S, Sun Q, Zhu J, Chen B, Xiong M, et al. Immuneinflammatory parameters in COVID-19 cases: a systematic review and meta-analysis. Front Med (Lausanne). 2020;7:301. doi: 10.3389/fmed.2020.00301. [PubMed: 32582743].

16. Xiang N, Havers F, Chen T, Song Y, Tu W, Li L, et al. Use of national pneumonia surveillance to describe influenza A(H7N9) virus epidemiology, China, 2004-2013. Emerg Infect Dis. 2013;19(11):1784-90. doi: 10.3201/eid1911.130865. [PubMed: 24206646].

17. Liu J, Liu Y, Xiang $\mathrm{P}, \mathrm{Pu}$ L, Xiong $\mathrm{H}, \mathrm{Li} \mathrm{C}$, et al. Neutrophil-tolymphocyte ratio predicts critical illness patients with 2019 coronavirus disease in the early stage. J Transl Med. 2020; 18(1):206. doi: 10.1186/s12967-020-02374-0. [PubMed: 32434518].

18. Di Micco P, Russo V, Carannante $N$, Imparato $M$, Rodolfi $S$, Cardillo G, et al. Clotting factors in COVID-19: epidemiological association and prognostic values in different clinical presentations in an Italian cohort. J Clin Med. 2020;9(5):1371. doi: 10.3390/jcm9051371. [PubMed: 32392741].

19. Zheng Z, Peng F, Xu B, Zhao J, Liu H, Peng J, et al. Risk factors of critical \& mortal COVID-19 cases: a systematic literature review and meta-analysis. J Infect. 2020;81(2):e16-25. doi: 10.1016/j.jinf.2020.04.021. [PubMed: 32335169]. 